\title{
Predictors of distress and quality of life in patients undergoing cancer therapy: impact of treatment type and decisional role
}

\author{
Thomas F. Hack 1,2*, Tom Pickles ${ }^{3,4}$, J. Dean Ruether ${ }^{5,6}$, Lorna Weir ${ }^{3,4}$, Barry D. Bultz ${ }^{5,6}$, John Mackey ${ }^{7,8}$ \\ and Lesley F. Degner' \\ 'Faculty of Nursing, University of Manitoba, Winnipeg, MB, Canada \\ ${ }^{2}$ CancerCare Manitoba, Winnipeg, MB, Canada \\ ${ }^{3}$ British Columbia Cancer Agency, Vancouver, BC, Canada \\ ${ }^{4}$ Faculty of Medicine, University of British Columbia, BC, Canada \\ ${ }^{5}$ Tom Baker Cancer Centre, Calgary, AB, Canada \\ ${ }^{6}$ Faculty of Medicine, University of Calgary, $A B$, Canada \\ ${ }^{7}$ Cross Cancer Institute, Edmonton, $A B$, Canada \\ ${ }^{8}$ Faculty of Medicine, University of Alberta, Edmonton, AB, Canada
}

* Correspondence to: Asper Clinical Research Institute/St Boniface Research Centre, Room CR3018, 35I Taché Avenue, Winnipeg, Man Canada R2H $2 A 6$

E-mail: thack@sbrc.ca
Received: 14 April 2009

Accepted: 23 April 2009

\begin{abstract}
Purpose: The purpose of this secondary investigation was to examine the impact of the type of treatment received and the perceived role in treatment decision making in predicting distress and cancer-specific quality of life in patients newly diagnosed with breast or prostate cancer.

Method: Participants included 1057 newly diagnosed breast and prostate cancer patients from four Canadian cancer centers who partook in a randomized controlled trial examining the utility of providing patients with an audio-recording of their treatment planning consultation. A MANCOVA was performed to predict distress and cancer-specific quality of life at 12 weeks post-consultation based on control variables (patient age, education, residence, tumor size (breast sample), gleason score (prostate sample), and receipt of an initial treatment consultation recording), predictor variables (treatment type-chemotherapy, hormone therapy, radiation therapy; decisional role-active, collaborative, passive), and interactions between these predictors.

Results: Women who received chemotherapy and reported having played a more passive role in treatment decision making had significantly greater distress and lower cancer-specific quality of life at 12-week post-consultation. There were no statistically significant predictors of these outcomes identified for men with prostate cancer.

Conclusion: Receipt of chemotherapy places women with breast cancer at risk for distress and reduced quality of life, but only for the subset of women who report playing a passive role in treatment decision making. Prospective, longitudinal studies are needed to confirm the present findings and to explicate the antecedents, composition, and consequences of the 'passive' decisional role during the treatment phase of the cancer trajectory. Copyright (C) 2009 John Wiley \& Sons, Ltd.
\end{abstract}

Keywords: cancer; oncology; treatment; psychosocial; adjustment; patient-physician; prostate cancer; breast cancer

\section{Introduction}

A diagnosis of cancer is accompanied by a myriad of medical and psychosocial challenges. The first six months post-diagnosis can be overwhelming for patients who must manage their emotional responses to the diagnosis, treatment plan, and side effects of treatment. Declines in physical functioning, fears surrounding the uncertainty of the prognosis and treatment, and doubts as to whether the illness will be overcome, may all compromise functional, social, emotional, and psychological well-being.

Adjuvant treatments for breast cancer have their known physical side effects and psychosocial correlates. Chemotherapy, for example, is associated most commonly with hair loss, nausea, and fatigue. The prevalence of chemotherapyrelated fatigue has been estimated at $26 \%$ [1]. This fatigue is chronic in some patients who receive chemotherapy - compared with more acute fatigue effects associated with radiation therapy [2] - and 
chemotherapy-related fatigue significantly curtails activities of daily living [3]. The psychosocial impact of the physical effects associated with chemotherapy may be compounded by the cognitive effects associated with drug toxicities and the degree to which these agents may penetrate the blood-brain barrier [4-6]. Endocrine therapies are known to produce chronic menopausal symptoms in patients with breast cancer, and chemotherapy may induce early menopause in younger patients. Reviews of the use of hormonal therapies in breast cancer have called for detailed scrutiny of the impact on quality of life of these various treatments [7-8].

For patients with low-risk prostate cancer, equivalent survival rates are reported for the primary treatment options. Therefore, it has been argued that the choice of treatment should be based, in large part, on the degree to which a patient is willing to tolerate the side effects associated with these options, as well as the perceived relative convenience of these options. The most common side effects reported by men with prostate cancer are erectile and sexual dysfunction [9], and urinary incontinence, all of which may be accompanied by significant degrees of psychological distress and impairment to quality of life [10]. There is currently no single treatment regimen recommended as a 'best practice' option for these men, so it is increasingly common for oncologists to defer to their patients regarding the determination of the primary treatment course, or to work with their patients to formulate a treatment plan tailored to the prognosis, preferences of the patient, and anticipated side effects of treatment [11]. This decision is complicated by the fact that the severity of the physical and psychological effects differs according to which treatment is administered. The provision of psychoeducational support for men with prostate cancer is paramount given that many patients feel insecure about making an informed choice from among the available treatment options. Additional evidence on the impact of these treatments on quality of life will aid the decision-making process of men with early stage prostate cancer [12]. Psychoeducational support is particularly important for men with higher-risk prostate cancer, for whom treatment considerations may involve a weighing of the survival benefits of treatment against the toxicities and quality of life decrements associated with these treatments [13].

The purpose of this study was to examine the relationships between the various types of treatment that breast and prostate cancer patients receive either subsequently to, or as an alternative to, any primary surgery (lumpectomy, mastectomy, or radical prostatectomy), decisional role, and aspects of psychosocial well-being (patient- reported distress and cancer-specific quality of life) measured 12 weeks after (T2) the primary treatment (adjuvant treatment in the case of breast cancer patients) consultation (T1).

The development of hypotheses was guided by the modified theoretical framework of the coping process [14]. According to this framework, involvement in treatment decision making may be regarded as a coping response to the perceived threats, challenges, and harms associated with cancer treatment and its associated side effects. To the extent that the coping response yields unfavorable consequences, there may be resultant distress and reduced quality of life. If the coping response yields favorable outcomes, or if hope or meaning can be established out of initially unfavorable outcomes, then well-being may be enhanced. Support for this model may be found in the finding that approach-based coping responses are significantly predictive of positive adjustment in women with breast cancer through the first year following diagnosis, particularly for those women with high levels of hope [15]. In the present study, it was hypothesized that receipt of any of the treatments (chemotherapy, hormone therapy, and radiation therapy), when examined independently of other treatments, would be significantly associated with higher distress and lower cancer-specific quality of life at the 12-week follow-up, in comparison to patients who did not receive the said treatment. In addition, the role that patients reported having actually played in treatment decision making was measured, and interactions between decisional role and treatment type were evaluated. The patient's reported actual role, rather than expressed preferred role, was measured because prior studies have reported that the former is a stronger predictor of quality of life [16], satisfaction with the initial treatment consultation, and the amount of information and emotional support received from oncologists [17] than is preferred role or role congruence. It was hypothesized that those patients who reported having been active participants in their treatment planning would experience less distress and better cancer-specific quality of life at the 12-week follow-up than patients who indicated they deferred treatment decision matters to their oncologists.

\section{Methods}

\section{Patient sample}

All patients participated in a randomized controlled trial examining the efficacy of providing newly diagnosed cancer patients with an audiotaped recording of their primary treatment consultation (findings specific to the benefits of the 
consultation recording were previously published [18-19]). All eligible patients were invited to participate in the study. Eligible patients included those women and men with confirmed diagnoses of breast or prostate cancer, respectively, who presented to either a tertiary or community oncology clinic for their primary adjuvant treatment (breast) or primary treatment (prostate) consultation. All patients were older than 18 years of age and were discerned to be free of any cognitive impairment or other limiting factor precluding their ability to provide informed consent. Patients were accrued from six cancer treatment facilities in four Canadian cities, and data analyses were run on a final sample of 1057 patients (627 women and 430 men). The patients were recruited from the clinics of 51 medical and radiation oncologists at the $\mathrm{BC}$ Cancer Agency, Vancouver, Canada $(n=18)$, the Tom Baker Cancer Centre, Calgary, Canada $(n=13)$, CancerCare Manitoba, Winnipeg, Canada $(n=9)$, and the Cross Cancer Institute, Edmonton, Canada $(n=11)$.

\section{Procedures}

The study protocol was approved by the authoritative review committees for ethics in human subjects research at each of the collaborating institutions, and all patients provided informed, written consent to be study participants.

Prior to the treatment consultation, the clinical research nurse obtained informed consent and administered a patient sociodemographic and illness profile. The follow-up measures were then given to the patient in a sealed envelope with an instruction to keep the envelope sealed until contacted by the research nurse approximately 12 weeks later, at which time the nurse phoned the patient to record the answers to the questionnaire items as provided by the patient via telephone. Patient medical records were reviewed by the research nurse after the initial course of treatment had ended to document the various treatments received during the 12 -week study interval.

\section{Variables and instruments}

At 12 weeks post-consultation, the following questionnaires were completed: (i) Control Preferences Scale-assumed role [20-22]; (ii) Profile of Mood States (POMS) [23]; and (iii) Functional Assessment of Cancer Therapy (FACT-B; FACT-P) [24].

The clinical research nurse administered an adapted form of the Control Preferences Scale [20-22] to assess the role in decision making that the patient assumed. The scale is composed of five statements that correspond to active ('I made the decision about which treatment I will receive'; 'I made the final decision about my treatment after seriously considering my doctor's opinion'), colla- borative ('My doctor and I shared responsibility for deciding which treatment is best for me'), and passive ('My doctor made the final decision about which treatment will be used, but seriously considered my opinion'; 'I left all decisions regarding treatment to my doctor') roles in decision making. Patients indicated the one statement that best represented them.

Psychological distress was measured using the POMS [23], a 65-item measure of general emotional disturbance. Seven subscales, including depression, anxiety, confusion, fatigue, anger, vigor, and friendliness, comprise this measure. To more clearly differentiate between positive and negative effect, a POMS negative score was calculated by summing the five negative subscales [25]. Likewise, the two positive subscales were summed to yield a POMS positive score. For this pooled sample, Cronbach's coefficient alphas ranged from 0.33 (depression) to 0.78 (vigor) for the seven POMS subscales.

The FACT-B (version 4) and FACT-P (version 4) are 36-item and 39-item, respectively, self-report measures developed to assess the quality of life of women and men diagnosed with breast and prostate cancer [24]. The measures include the 27-item FACT-G, which is composed of four primary subscales - physical well-being, social/family wellbeing, emotional well-being, and functional wellbeing, and either 9 or 12 additional items of concern specific to women with breast cancer, or men with prostate cancer, respectively. These measures have robust psychometric properties for both the total score and each of the subscale scores, and have been shown to be sensitive to meaningful clinical change [26-28]. For the women in this study, Cronbach's alpha for total score at follow-up was 0.82, while the subscale Cronbach alphas ranged from 0.74 (functional well-being) to 0.84 (social/ family well-being). For the men, Cronbach's coefficient alpha for total score at follow-up was 0.79, while the subscale Cronbach's coefficient alphas ranged from 0.70 (functional well-being) to 0.80 (social/family well-being).

\section{Data analyses}

Unix SAS V 9.1 software was used for all analyses. Descriptive statistics and correlation matrices were generated for all measures, and raw and standardized Cronbach's alpha coefficients were generated for the outcome measures.

To examine the relationship between decisional role, treatment received, and the outcome variables (distress and cancer-specific quality of life), the breast and prostate samples were examined independently. A multivariate analysis of covariance (MANCOVA) was run as the initial step, in which all the dependent variables were simultaneously analyzed. Univariate regression tests were subsequently performed only if the multivariate test was 
significant at an alpha level of 0.05 . The initial use of the MANCOVA served to control for the Type 1 error rate and avoid having to use a Bonferroni correction in the subsequent series of univariate regression analyses, thereby allowing the use of a 0.05 alpha level of significance in these tests [29]. The control variables for the MANCOVA were patient age, education, and residence (urban/rural), tumor size (breast sample), gleason score (prostate sample), and receipt of an initial treatment consultation recording (yes/no). The predictor variables were treatment type (chemotherapy, hormone therapy, radiation therapy), decisional role (active, collaborative, passive), and interactions betweens these predictors. Each treatment was considered to have been received if administered at some point during the interval between the treatment consultation and the 12-week follow-up assessment.

For an indication of disease severity, tumor size was selected over the number of positive nodes in the breast cancer model given its greater statistical power in the subsequent univariate analyses. The correlations between tumor size and receipt of chemotherapy and between number of positive nodes and receipt of chemotherapy were 0.290 $(p<0.0001)$ and $0.474(p<0.0001)$, respectively. To minimize the loss of statistical power due to missing tumor size data $(n=39)$, the univariate regression analyses were run with and without the inclusion of this variable. Given the highly significant correlation between tumor size and receipt of chemotherapy, the introduction of tumor size to a model that already included chemotherapy treatment rarely resulted in a different final model. Results are therefore reported for the univariate regression analyses run without the inclusion of tumor size, except for the rare occurrence when the two models differed, i.e. a change in statistical significance, and for which both model solutions are therefore presented. Significant interactions in the univariate regressions were subsequently analyzed using Tukey's Honestly Significant Difference test to determine the direction of significance, with scores adjusted for covariates.

\section{Results}

\section{Sample}

Of the 1270 eligible patients approached to participate in this study (785 women with breast cancer; 485 men with prostate cancer), 134 (115 women, 19 men) declined the offer, including 5 women who brought their own recording equipment to the consultation. Of the remaining 1136 patients who signed the consent form, 74 did not complete the study. Reasons for not continuing included being dissatisfied with the assigned experimental group $(n=7)$, having to wait too long to see the oncologist $(n=1)$, withdrawing for unspecified reasons or inability to contact patient prior to follow-up assessment $(n=40)$, death $(n=1)$, too ill $(n=5)$ to participate, and audiotape equipment malfunction $(n=16)$ or unavailability $(n=4)$. In addition, 4 patients were excluded for being improperly randomized, and 1 was excluded for having a non-primary, recurrent cancer, leaving a final sample of 1057 patients (627 women; 430 men) and a response rate of $83.2 \%$. For the women, the mean tumor size was $1.96 \mathrm{~cm}$ $(\mathrm{SD}=1.55 \mathrm{~cm})$. For the men, the mean prostatespecific antigen was $13.3(\mathrm{SD}=19.9)$ and the mean Gleason score was $6.6(\mathrm{SD}=1.0)$. Demographic summary information is listed in Table 1.

\section{Treatment}

The mean number of days spanning the date of the treatment consultation (T1) to the 12-week followup (T2) interval was $84.2(\mathrm{SD}=8.2)$ for the breast sample and $88.3(\mathrm{SD}=17.5)$ for the prostate sample, with $96 \%$ of the breast sample falling into a T1-T2 interval of $80-99$ days, and $61.7 \%$ of the prostate sample lying within this interval. The percentage of the breast sample that received

Table I. Patient demographic information $(n=1057)$

\begin{tabular}{|c|c|c|}
\hline \multirow[b]{2}{*}{ Patient information } & \multicolumn{2}{|c|}{ No. of patients (\%) } \\
\hline & Breast $(n=627)$ & Prostate $(n=430)$ \\
\hline \multicolumn{3}{|l|}{ Location of consultation } \\
\hline Calgary & $232(37.0)$ & I56 (36.3) \\
\hline Vancouver & $215(34.3)$ & $198(46.0)$ \\
\hline Winnipeg & $105(16.7)$ & $76(17.7)$ \\
\hline Edmonton & $75(12.0)$ & $0(0.0)$ \\
\hline \multicolumn{3}{|l|}{ Age, years } \\
\hline$<45$ & $97(15.5)$ & I (0.2) \\
\hline $45-54$ & $206(32.9)$ & $27(6.3)$ \\
\hline $55-59$ & $96(15.3)$ & $46(10.7)$ \\
\hline $60-64$ & $65(10.4)$ & $59(13.7)$ \\
\hline $65-69$ & $57(9.1)$ & $105(24.4)$ \\
\hline $70-74$ & $46(7.3)$ & $110(25.6)$ \\
\hline$\geqslant 75$ & $60(9.6)$ & $82(19.1)$ \\
\hline Mean age (SD) & $56.5(12.0)$ & $67.4(7.6)$ \\
\hline \multicolumn{3}{|l|}{ Education } \\
\hline$\leqslant$ Grade 10 & $85(13.6)$ & $129(30.0)$ \\
\hline Grades $11-13$ & $206(32.8)$ & $113(26.3)$ \\
\hline > High school & $336(53.6)$ & $187(43.5)$ \\
\hline Not reported & - & I $(0.2)$ \\
\hline \multicolumn{3}{|l|}{ Marital status } \\
\hline Married/Common law & $433(69.1)$ & $361(84.0)$ \\
\hline Divorced/Separated & $74(11.8)$ & $26(6.0)$ \\
\hline Widowed & $79(12.6)$ & $25(5.8)$ \\
\hline Never married & $41(6.5)$ & $17(4.0)$ \\
\hline Not reported & - & I $(0.2)$ \\
\hline \multicolumn{3}{|l|}{ Residence } \\
\hline Urban & $449(7 \mid .6)$ & $314(73.0)$ \\
\hline Rural & 177 (28.2) & I I 6 (27.0) \\
\hline Not reported & $\mathrm{I}(0.2)$ & - \\
\hline
\end{tabular}


chemotherapy at some point within the T1-T2 study period was 34.6 , with $35.4 \%$ receiving hormone therapy, and $42.1 \%$ receiving radiation therapy. For the prostate sample, $61.0 \%$ received hormone therapy during the T1-T2 interval and $27.7 \%$ were given radiation therapy. The percentages of the breast sample that received only chemotherapy, hormone therapy, or radiation therapy during this time period were $30.7,11.2$, and $19.4 \%$, respectively. Among the men, $47.8 \%$ received only hormone therapy and $14.4 \%$ received only radiation therapy. Several patients received more than 1 treatment modality during the T1-T2 interval: Breast: chemotherapy and hormone therapy$2.7 \%$; chemotherapy and radiation therapy $-1.3 \%$; radiation therapy and hormone therapy $-21.4 \%$; Prostate: radiation and hormone therapy- $13.2 \%$. The temporal details of treatment (chemotherapy, hormone therapy, and radiation therapy) received either supplementary or preferentially to surgical management are presented in Table 2.

Among those women who received a portion of their treatment within the T1-T2 assessment interval, the average number of days on chemotherapy, hormone therapy, and radiation therapy within the T1-T2 interval was 63.1, 66.3, and 25.9 , respectively. The men received hormone therapy on an average of 75.7 days during the T1-T2 interval, and $37.2 \%$ received radiation therapy during this same time period.

\section{Decisional control}

Patients' assumed role in treatment decision making, reported at the T2 follow-up, is listed in Table 3 . The collaborative role was the most widely endorsed role by the women (42.7), followed by active and then passive. Among the men, the active role was most common (39.7), followed by the collaborative and then passive role.

\section{Regression analyses}

Sample means and SDs for each outcome variable are listed, according to treatment received, in Table 4. For the breast sample MANCOVA, Pillai's trace statistic was significant for age, education and receipt of a consultation recording but not for tumor size or residence. Among the predictor variables, chemotherapy and hormone therapy were statistically significant, as was decisional role. Radiation therapy was not significant. Among the interaction terms, only the interaction of chemotherapy and decisional role was significant and therefore included in subsequent tests. The MANCOVA for the prostate sample demonstrated no significant predictors - age was the only significant control variable - and therefore no univariate tests were performed; the outcomes of interest were not related

Table 3. 12-weeks post-consultation assumed role in treatment decision making*

\begin{tabular}{llclc}
\hline Role & $\begin{array}{c}\text { Active } \\
\text { No.(\%) }\end{array}$ & $\begin{array}{c}\text { Collaborative } \\
\text { No.(\%) }\end{array}$ & $\begin{array}{c}\text { Passive } \\
\text { No.(\%) }\end{array}$ & Total \\
\hline Breast sample & $211(34.5)$ & $261(42.7)$ & $139(22.7)$ & 611 \\
Prostate sample & $161(39.7)$ & $131(32.3)$ & $114(28.1)$ & 406 \\
Total & 372 & 392 & 253 & 1017 \\
\hline
\end{tabular}

*Breast sample size $<627$ given 14 patients who reported that 'no treatment decision was made' and missing outcome values for 2 patients. Prostate sample size $<430$ given 10 patients who indicated that 'no treatment decision was made' and missing outcome values for 14 patients.

Table 2. Patient treatment information

\begin{tabular}{|c|c|c|c|}
\hline & \multicolumn{3}{|c|}{ No. of patients (\%) } \\
\hline & Radiation & Hormone & Chemotherapy \\
\hline \multicolumn{4}{|l|}{ Breast $(n=627)$} \\
\hline Commenced pre-TI and finished pre-TI & $6(1.3)$ & I (0.2) & $3(1.3)$ \\
\hline \multicolumn{4}{|l|}{ Received during $T I-T 2$ interval } \\
\hline Commenced pre-TI and finished pre-T2 & $0(0)$ & I (0.3) & $5(2.2)$ \\
\hline Commenced pre-TI and finished post-T2 & I $(0.2)$ & $103(28.8)$ & $3(1.3)$ \\
\hline Commenced post-TI and finished pre-T2 & $231(51.3)$ & $3(0.8)$ & $61(27.0)$ \\
\hline Commenced post-TI and finished post-T2 & $31(6.9)$ & $113(31.6)$ & $147(65.0)$ \\
\hline Commenced post-T2 and finished post-T2 & $|8|(40.2)$ & $137(38.3)$ & $7(3.0)$ \\
\hline Total & $450(100)$ & $358(100)$ & $226(100)$ \\
\hline \multicolumn{4}{|l|}{ Prostate $(n=430)$} \\
\hline Commenced pre-TI and finished pre-TI & $3(1.0)$ & $7(2.4)$ & - \\
\hline \multicolumn{4}{|l|}{ Received during $T 1-T 2$ interval } \\
\hline Commenced pre-TI and finished pre-T2 & I (0.3) & $14(4.9)$ & - \\
\hline Commenced pre-TI and finished post-T2 & I (0.3) & $|4|(49.3)$ & - \\
\hline Commenced post-TI and finished pre-T2 & $61(20.3)$ & $21(7.3)$ & - \\
\hline Commenced post-TI and finished post-T2 & $54(18.0)$ & $82(28.7)$ & - \\
\hline Commenced post-T2 and finished post-T2 & $180(60.0)$ & $21(7.3)$ & - \\
\hline Total & $300(100)$ & $286(100)$ & - \\
\hline
\end{tabular}


Table 4. Mood state and quality of life 12 -weeks post-consultation

\begin{tabular}{|c|c|c|c|c|c|}
\hline \multirow{2}{*}{ Variable } & \multicolumn{3}{|c|}{ Breast } & \multicolumn{2}{|c|}{ Prostate } \\
\hline & $\begin{array}{l}\text { Chemo-therapy } \\
\text { Mean (SD) } \\
(n=216)\end{array}$ & $\begin{array}{l}\text { Hormone therapy } \\
\text { Mean (SD) } \\
(n=220)\end{array}$ & $\begin{array}{l}\text { Radiation therapy } \\
\text { Mean (SD) } \\
(n=263)\end{array}$ & $\begin{array}{l}\text { Hormone therapy } \\
\text { Mean (SD) } \\
(n=258)\end{array}$ & $\begin{array}{c}\text { Radiation therapy } \\
\text { Mean (SD) } \\
(n=\mid \text { I 7) }\end{array}$ \\
\hline \multicolumn{6}{|l|}{ Mood disturbance (POMS) } \\
\hline Fatigue & $12.1(6.9)$ & $8.1(6.8)$ & $8.6(7.0)$ & $6.6(6.4)$ & $6.1(5.3)$ \\
\hline Anger & $8.0(7.9)$ & $4.2(5.7)$ & $4.5(6.6)$ & $4.9(6.7)$ & $4.2(5.6)$ \\
\hline Vigor & $3.6(6.9)$ & I $6.0(5.8)$ & $15.9(6.0)$ & |8.| (6.2) & $19.0(5.5)$ \\
\hline Confusion & $7.2(4.6)$ & $5.4(4.1)$ & $5.4(4.4)$ & $5.3(4.4)$ & $4.7(3.7)$ \\
\hline Depression & $10.7(10.0)$ & $6.1(7.7)$ & $6.1(8.4)$ & $5.3(7.9)$ & $4.4(6.8)$ \\
\hline Anxiety & $10.6(6.5)$ & $7.8(6.4)$ & $7.8(6.8)$ & $7.0(6.3)$ & $6.2(6.8)$ \\
\hline Friendliness & $16.8(4.6)$ & $18.9(3.9)$ & $19.0(3.9)$ & $18.9(4.8)$ & $19.6(4.0)$ \\
\hline POMS positive & $30.3(10.7)$ & $34.9(8.9)$ & $34.9(9.2)$ & $36.9(10.3)$ & $38.6(8.7)$ \\
\hline POMS negative & $48.6(30.0)$ & $31.6(26.0)$ & $32.3(28.3)$ & $29.1(27.7)$ & $25.7(22.8)$ \\
\hline True POMS & $35.0(34.3)$ & $15.6(29.6)$ & $16.4(32.0)$ & II.I (31.3) & $6.6(25.6)$ \\
\hline \multicolumn{6}{|l|}{ Quality of life (FACT-B/P) } \\
\hline Physical & $18.0(6.0)$ & $22.9(4.7)$ & $22.7(4.7)$ & $24.3(3.7)$ & $24.3(24.4)$ \\
\hline Social & $22.5(4.9)$ & $23.2(4.8)$ & $23.1(4.8)$ & $22.4(4.4)$ & $23.5(3.8)$ \\
\hline Emotional & $18.0(4.4)$ & $20.0(3.8)$ & $20.0(3.8)$ & $20.3(3.7)$ & $21.5(3.4)$ \\
\hline Functional & $17.2(5.6)$ & $21.0(5.3)$ & $21.0(5.1)$ & $22.1(5.0)$ & $22.8(4.6)$ \\
\hline Breast/Prostate-specific concerns & $21.0(6.3)$ & $26.3(5.2)$ & $26.6(5.4)$ & $35.6(6.2)$ & $35.9(6.0)$ \\
\hline FACT-G & $75.7(16.2)$ & $87.0(\mid 4.1)$ & $86.6(14.1)$ & $89.2(12.7)$ & $92.1(11.1)$ \\
\hline $\mathrm{FACT}-\mathrm{B} / \mathrm{P}$ & $97.6(20.6)$ & I I3.2(17.6) & $113.2(17.7)$ & $124.8(17.2)$ & $128.1(15.5)$ \\
\hline
\end{tabular}

in a statistically significant manner to receipt of hormone or radiation therapy.

The results of the univariate analyses for the breast sample are presented in Table 5. With respect to mood disturbance, there were significant main effects of chemotherapy for each of the POMS subscales; comparisons of means showed that patients who received chemotherapy had greater mood disturbance (higher negative and lower positive mood scores) than patients who did not receive chemotherapy. With the exception of POMS anger, there were significant main effects of decisional role for all POMS negative, but not POMS positive, subscales. Furthermore, statistically significant interactions between chemotherapy and decisional role were observed for the POMS anger and depression subscales, the sum of the POMS negative subscales, and the True POMS. These interactions are plotted in Figure 1. More detailed analysis of these significant interactions showed that the effect of chemotherapy was significantly related to mood state only for women who played a passive role in treatment decision making, not for women who did not adopt this role. Among women who received chemotherapy, those who played a more passive role had the:

(i) highest levels of anger $(F(2,586)=4.89$, $p=0.008$ ) (passive patients had significantly higher anger levels than collaborative patients $(p=0.025))$;

(ii) highest reported depression $(F(2,586)=7.13$, $p<0.001$ ) (passive patients had greater depression than both collaborative $(p=0.006)$ and active ( $p=0.020)$ patients);

(iii) highest POMS negative subscales total score $(F(2,586)=7.06, p<0.001)$ (passive patients had higher negative mood than both collaborative $(p=.004)$ and active $(p=0.034)$ patients); and

(iv) highest overall mood disturbance $(F(2,586)=6.85, p=0.001)$ (passive patients had greater overall mood disturbance than collaborative $(p=0.006)$ and active ( $p=0.031)$ patients).

Age was a significant predictor of POMS anger confusion, depression, anxiety, negative subscale sum, and true score, with younger women reporting more distress than older women. Patients with post-secondary education were significantly less depressed than patients who completed 10 or fewer years of school, and significantly angrier than patients who completed high school only.

With respect to quality of life, there were significant main effects of chemotherapy for each of the FACT-B subscales, with the exception of the social well-being subscale. Comparisons of means showed that patients who received chemotherapy reported a lower quality of life than patients who did not receive chemotherapy. There were significant main effects of decisional role for the emotional and functional subscales and the FACT-G and FACT-B scores. Significant interactions between chemotherapy and decisional role were observed for the functional well-being subscale and the FACT-G score. These 
Table 5. Breast sample regression findings

\begin{tabular}{|c|c|c|c|c|}
\hline & $R$-square & F-value & df & $P$-value \\
\hline \multicolumn{5}{|l|}{ Mood disturbance (POMS) } \\
\hline Fatigue & 0.099 & 4.85 & 13,573 & $<0.000 \mid$ \\
\hline Chemotherapy & & 24.91 & I,573 & $<0.0001$ \\
\hline Decisional role & & 4.97 & 2,573 & 0.007 \\
\hline Anger & 0.130 & 6.59 & 13,573 & $<0.0001$ \\
\hline Age & & 26.36 & 1,573 & $<0.0001$ \\
\hline Education & & 5.22 & 2,573 & 0.006 \\
\hline Chemotherapy & & 3.73 & ।,573 & $0.054^{*}$ \\
\hline Chemotherapy*DECISIONAL ROLE & & 4.87 & 2,573 & 0.008 \\
\hline Vigor & 0.049 & 2.27 & 13,573 & 0.006 \\
\hline Chemotherapy & & 18.12 & ।,573 & $<0.0001$ \\
\hline Confusion & 0.087 & 4.21 & 13,573 & $<0.0001$ \\
\hline Age & & 9.78 & ।,573 & 0.002 \\
\hline Chemotherapy & & 9.27 & 1,573 & $<0.001$ \\
\hline Decisional role & & 4.44 & 2,573 & 0.012 \\
\hline Depression & 0.123 & 6.19 & 13,573 & $<0.0001$ \\
\hline Age & & 12.32 & ।,573 & $<0.001$ \\
\hline Education & & 4.29 & 2,573 & 0.014 \\
\hline Chemotherapy & & 18.63 & I,573 & $<0.0001$ \\
\hline Decisional role & & 6.49 & 2,573 & 0.002 \\
\hline Chemotherapy*DECISIONAL ROLE & & 3.41 & 2,573 & 0.034 \\
\hline Anxiety & 0.084 & 4.05 & 13,573 & $<0.0001$ \\
\hline Age & & 12.23 & I,573 & $<0.001$ \\
\hline Chemotherapy & & 9.31 & 1,573 & 0.002 \\
\hline Decisional role & & 3.22 & 2,573 & 0.041 \\
\hline Friendliness & 0.083 & 3.88 & 13,573 & $<0.0001$ \\
\hline Chemotherapy & & 15.42 & ।,573 & $<0.0001$ \\
\hline POMS positive & 0.068 & 3.20 & |3,573 & $<0.0001$ \\
\hline Chemotherapy & & 20.03 & ।,573 & $<0.0001$ \\
\hline POMS negative & 0.135 & 6.89 & 13,573 & $<0.0001$ \\
\hline Age & & 16.27 & 1,573 & $<0.000 \mid$ \\
\hline Chemotherapy & & 18.06 & 1,573 & $<0.000 \mid$ \\
\hline Decisional role & & 5.77 & 2,573 & $<0.0001$ \\
\hline Chemotherapy*DECISIONAL ROLE & & 3.92 & 2,573 & 0.003 \\
\hline True POMS & 0.127 & 6.42 & 13,573 & $<0.0001$ \\
\hline Age & & 12.19 & ।,573 & $<0.001$ \\
\hline Chemotherapy & & 20.97 & ।,573 & $<0.000 \mid$ \\
\hline Decisional role & & 5.29 & 2,573 & 0.005 \\
\hline Chemotherapy*DECISIONAL ROLE & & 3.85 & 2,573 & 0.022 \\
\hline \multicolumn{5}{|l|}{ Quality of life (FACT-B) } \\
\hline Physical & 0.209 & 11.62 & 13,573 & $<0.0001$ \\
\hline Age & & 6.58 & ।,573 & $<0.011$ \\
\hline Chemotherapy & & 59.30 & 1,573 & $<0.0001$ \\
\hline Social & n.s. & & & \\
\hline Emotional & 0.119 & 5.95 & 13,573 & $<0.000 \mid$ \\
\hline Age & & 34.00 & ।,359 & $<0.000 \mid$ \\
\hline Chemotherapy & & 4.87 & 1,359 & 0.028 \\
\hline Decisional role & & 3.16 & 2,573 & 0.043 \\
\hline Functional & 0.150 & 7.76 & 13,573 & $<0.000 \mid$ \\
\hline Chemotherapy & & 45.24 & 1,573 & $<0.0001$ \\
\hline Decisional role & & 6.25 & 2,573 & 0.002 \\
\hline Chemotherapy*DECISIONAL ROLE & & 3.95 & 2,573 & 0.020 \\
\hline Breast-specific concerns & 0.179 & 9.61 & 13,573 & $<0.0001$ \\
\hline Age & & 17.03 & ।,573 & $<0.0001$ \\
\hline Chemotherapy & & 34.97 & 1,573 & $<0.0001$ \\
\hline FACT-G & 0.170 & 9.05 & 13,573 & $<0.0001$ \\
\hline Age & & 13.54 & ।,573 & $<0.001$ \\
\hline Chemotherapy & & 33.55 & I,573 & $<0.0001$ \\
\hline Decisional role & & 4.79 & 2,573 & 0.009 \\
\hline Chemotherapy*DECISIONAL ROLE & & 3.99 & 2,573 & 0.019 \\
\hline$F A C T-B$ & 0.198 & 10.88 & 13,573 & $<0.000 \mid$ \\
\hline Age & & 17.53 & 1,573 & $<0.000 \mid$ \\
\hline Chemotherapy & & 41.12 & 1,573 & $<0.000 \mid$ \\
\hline Decisional role & & 4.88 & 2,573 & 0.008 \\
\hline
\end{tabular}

${ }^{*}$ Chemotherapy was marginally significant in this model; significant $(p=0.029)$ in model that included tumor size. 


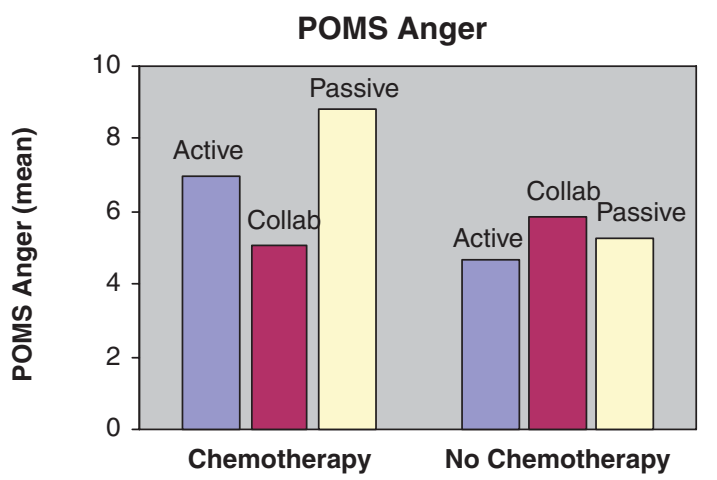

POMS Depression

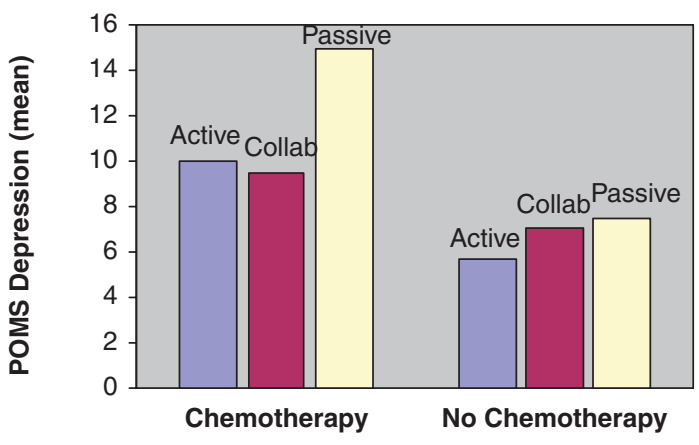

POMS Negative Subscales

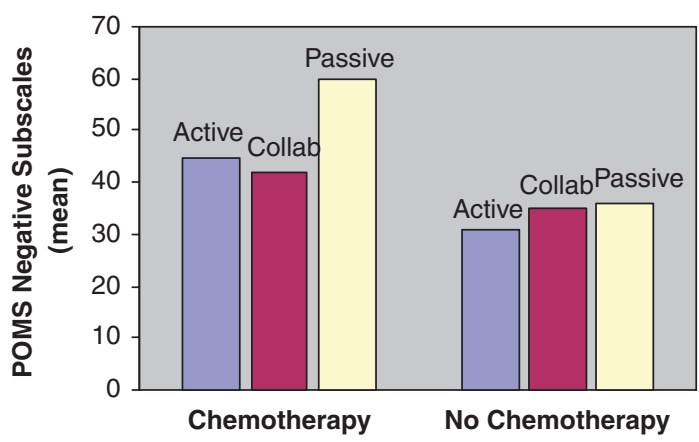

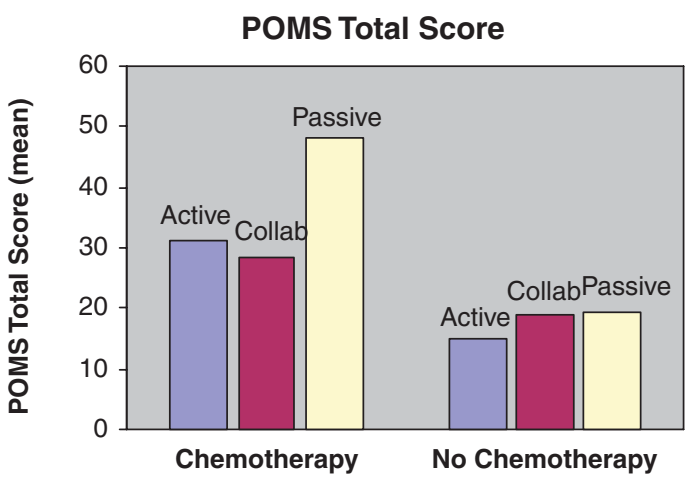

FACT Functional Well-being

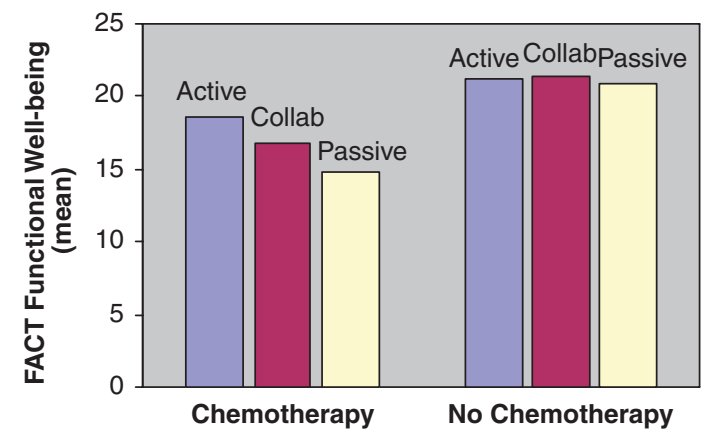

FACT-G

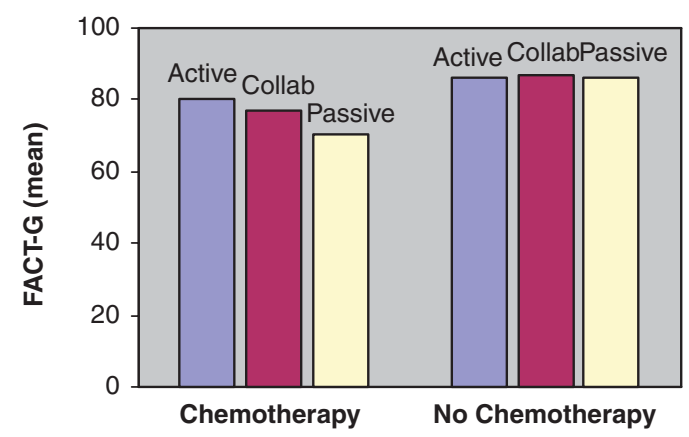

Figure I. Statistically significant interactions between chemotherapy and decisional role in the prediction of psychological distress and cancer-specific quality of life

interactions are also plotted in Figure 1. Closer scrutiny of these significant interactions showed that, like the POMS measure, the effect of chemotherapy was significantly related to quality of life for women who assumed a passive role in treatment decision making; not for those who did not play this role. Among women who received chemotherapy, those who reported a more passive role had the:

(i) lowest levels of functional well-being $(F(2,586)=8.13, p<0.001)$ (those who played a passive role had significantly lower quality of life than active patients $(p=0.001))$; and

(ii) lowest FACT-G scores $(F(2,586)=7.15$, $p<0.001$ ) (passive patients had lower scores than active patients $(p=0.002))$.

Age was a significant predictor of physical and emotional well-being, breast cancer-specific concerns, FACT-G score, and FACT-B score, with younger women reporting worse quality of life than older women.

\section{Discussion}

The findings of the present study indicate that not all women with breast cancer who receive chemotherapy experience the same associated degree of distress and decrement in quality of life; it is only those women who receive chemotherapy and report having played a passive role in treatment decision making who are significantly more likely to report distress at 12 weeks following the adjuvant treatment consultation. The clinical implication of this finding depends on the explanation given as to why the passive decision style is associated with greater distress and reduced quality of life in women 
receiving chemotherapy. The empirical relationship between known stressful life events-like chemotherapy-and distress is complex and well documented. In addition, it is known that passive involvement in treatment decision making is significantly associated with poorer emotional adjustment during adjuvant therapy and up to three years later. The known physical and psychosocial distress associated with chemotherapy may undermine a patient's sense of control over medical circumstances, leaving that patient more vulnerable to additional distress. An essential issue yet to be empirically addressed is the relative contribution of patient factors (e.g. age, education, social support), contextual factors (knowledge of, and confidence in the healthcare system, the nature and strength of the patient-physician relationship), and disease and treatment factors (e.g. disease stage, prognosis, symptom profile, treatment side effects) to the patient's decisional role response. It is possible that the passive decision style is 'imposed' on the patient by factors associated with the medical context, such as the communication style of the health professional, that serve to erode a patient's perceived ability to contribute effectively to decisions affecting her or his medical treatment, thereby raising the level of distress. One study reported that while white and better educated patients were more active participants in consultations, the strongest predictor of patient involvement was a physician communication style marked by supportive talk and partnership building [30]. The clinical implication of this possibility is that health-care professionals should encourage patients to be active treatment consumers by providing them with necessary information and decision support within a clinical atmosphere characterized by empathy and partnership.

Another possibility is that a composite of patient factors (e.g. older age, lack of education, weak social support, anxious-reserved personality, learned avoidance responses to stress) causes some individuals to withdraw as an adaptive response to situations perceived as stressful. If this is the case, then interventions designed to persuade passive patients to be more active might backfire. It may therefore be better to consider passivity as a risk factor for emotional distress; a factor that might be best addressed by providing tailored psychosocial and educational resources to address the origins of the avoidance behavior and associated distress.

It is beyond the scope of this cross-sectional study to ascertain the causal direction of the relationship between chemotherapy, passive decision style, distress, and quality of life. Prospective, longitudinal designs are required to do so, and these studies should improve upon the current study by including baseline measures of the outcome variables. In the absence of baseline measures in the present study, the degree to which pretreatment levels of distress and quality of life are stronger predictors of these variables at 12 weeks post-consultation than either chemotherapy and its effects or decisional role remains undetermined.

The findings showed a significant relationship between treatment, distress, and quality of life for women with breast cancer but not for men with prostate cancer. One possible explanation for this gender discrepancy is the differences in the side effect profiles of the treatments for these two types of cancer, keeping in mind that none of the men in this study received chemotherapy. It is also possible that gender differences in psychological and physical symptom reporting might contribute to the findings [31]; this hypothesis should be examined in cancer disease sites common to both sexes, e.g. colorectal, lung.

While this study is an improvement over prior studies that failed to note the interval duration during which chemotherapy was administered, future studies should also record the chemotherapy agent and dosing schedule that patients receive. This will allow for a detailed assessment of the contribution of various agents and dosing regimens to psychological adjustment. While a few studies have examined the differences in quality of life, symptoms, and well-being among breast cancer patients enrolled in clinical trials comparing chemotherapy agents [32] dose schedules [33], or endocrine drugs [34-35], future studies should document the kind and amount of side effects experienced while on adjuvant treatment to track the impact of various side effects and on distress, well-being, and quality of life. It is not yet known, for example, whether hair loss is associated with greater overall distress than is nausea, fatigue, concentration and memory difficulties, or some combination of these side effects. For men with prostate cancer, it is not yet known whether particular side effects are associated with different degrees of adjustment.

While previous research has documented a significant relationship between the passive role and reduced quality of life among women with breast cancer [16], additional research is needed to shed light on how distress is developed and maintained in patients undergoing chemotherapy, and the role that treatment side effects play in exacerbating cognitive, behavioral and emotional indicators of maladjustment. To our knowledge, this study is the first of its kind to report that decisional role moderates the effect of treatment on distress and quality of life. It is not fully known, however, what aspects of the passive role dispose patients undergoing chemotherapy to relatively poorer adjustment than their relatively more active counterparts. Previous research shows that patients who prefer passive involvement are likely to be older and less educated than active patients. 
Perhaps being less educated diminishes a patient's sense of personal agency in effecting change in the treatment course and subsequent health outcome. A lack of confidence in ability to personally manage ones cancer affairs may breed resigned acceptance of fate in the hands of particular oncology service providers.

There are interventions that lend themselves well to accommodating the coping needs and decisional role preference styles of cancer patients during the critical period of treatment decision making and treatment onset when psychological distress is known to be relatively high. There is empirical support for the use of prompt sheets, decision aids, and consultation recordings [36,37] as well as distress screening [38], cognitive-behavioral stress management programs [39], patient navigators [40], and psychosocial clinicians. The application of these interventions should take into consideration the decisional role preferences of patients, yet to date there has been no randomized controlled trial examining the relationship between decisional role and decision aid effectiveness [41]. While the findings of the present study demonstrate that the passive role compromises well-being in women receiving chemotherapy following breast cancer surgery, future research is needed to address the mechanisms by which the passive role moderates these effects. Furthermore, the construct of decisional role needs further validation. Little is known about the stability of decisional role, how it is related to personality attributes, culture, social support, and learned behavioral and physiological responses to the stress of cancer treatment.

\section{Acknowledgements}

The authors thank the following medical and radiation oncologists who accrued patients to this trial: BC Cancer Agency (Weir, Lim, Keyes, Jackson, Rheume, Ragaz, Bryce, Gelmon, Tyldlesly, Chia, Campbell, Olivotto, Kim-Sing, Pickles, Morris, Wu, McKenzie, Duncan); Tom Baker Cancer Centre (Ruether, Paterson, Trotter, Husain, Smith, Krahn, Stewart, Craighead, Corbett, Angyalfi, Lau, Balogh, Ernst); CancerCare Manitoba (Bowman, Grenier, Cooke, Wong, Olweny, Butler, Harris, Schroeder, Chowdhury), and Cross Cancer Institute (Mackey, Tonkin, Severin, Smylie, Modie, Mehta, Lees, Koski, Au, Salter, Chafe). The authors also thank Ruth Bond and Dan Chateau for their statistical analysis of the data and valuable comments on the manuscript, and Betty-Lou Shoemaker, Sheryl Rosenhek, Susan Banwell, Linda Tkachuk, Luella Sinha, Kathy Cullihall, Sarah Brown, and Pat Marcoux for gathering the data. Supported by research grant $\sharp 42881$ from the Canadian Institutes of Health Research (CIHR), with partnership funds from the St. Boniface Hospital Research Foundation, Winnipeg, Manitoba, Canada, and the Faculty of Nursing, University of Manitoba, Winnipeg, Canada; research grant $\sharp 010455$ from the Canadian Breast Cancer Research Alliance; and research team grant $\sharp 010283$ from the National Cancer Institute of Canada (NCIC) with funds from the Canadian Cancer Society (CCS) and the CCS/NCIC Sociobehavioural Cancer Research Network. Thomas F. Hack is supported by a Dorothy J. Lamont Scientist Award from the NCIC and the CIHR. Lesley F. Degner is supported by a Research Chair from the Canadian Health Services and Research Foundation and the CIHR.

\section{References}

1. Andrykowski MA, Schmidt JE, Salsman JM, Beacham AO, Jacobsen PB. Use of a case definition approach to identify cancer-related fatigue in women undergoing adjuvant therapy for breast cancer. J Clin Oncol 2005; 23:6613-6622.

2. Jacobsen PB, Stein K. Is fatigue a long-term side effect of breast cancer treatment? Cancer Control 1999;6: 256-263.

3. de Jong N, Candel MJJM, Schouten HC, Abu-Saad HH, Courtens AM. Course of the fatigue dimension activity level and the interference of fatigue with daily living activities for patients with breast cancer receiving adjuvant chemotherapy. Cancer Nurs 2006;29(5):E1-E13.

4. Meyers CA. Neurocognitive dysfunction in cancer patients. Oncology 2000;14:75-79.

5. Olin JJ. Cognitive function after systemic therapy for breast cancer. Oncology 2001;15:613-618.

6. Schagen SB, Muller MJ, Boogerd W, van Dam FSAM. Cognitive dysfunction and chemotherapy: neuropsychological findings in perspective. Clin $\mathrm{Br}$ Cancer 2002;3(Suppl 3):S100-S108.

7. Coster S, Fallowfield LJ. The impact of endocrine therapy on patients with breast cancer: a review of the literature. Breast 2002;11:1-12.

8. Fallowfield LJ. Evolution of breast cancer treatments: current options and quality-of-life considerations. Eur $J$ Oncol Nurse 2004;8(Suppl 2):S75-S82.

9. Hollenbeck BK, Dunn RL, Wei JT, Sandler HM, Sanda MG. Sexual health recovery after prostatectomy, external radiation, or brachytherapy for early stage prostate cancer. Urol Rep 2004;5:212-219.

10. Bacon CG, Giovannucci E, Testa M, Glass TA, Kawachi I. The association of treatment-related symptoms with quality-of-life outcomes for localized prostate carcinoma patients. Cancer 2002;94:862-871.

11. O'Connor KM, Fitzpatrick JM. Side-effects of treatments for locally advanced prostate cancer. BJU Int 2006;97:22-28.

12. Penson DF, Litwin MS. Quality of life after treatment for prostate cancer. Curr Urol Rep 2003;4:185-195.

13. Pickles T. What's a man to do? Treatment options for localized prostate cancer. Can Fam Physician 2004;50: 65-72.

14. Folkman S. Positive psychological states and coping with severe stress. Soc Sci Med 1997;45:1207-1221.

15. Stanton AL, Danoff-Burg S, Huggins ME. The first year after breast cancer diagnosis: hope and coping strategies as predictors of adjustment. Psycho-Oncol 2002;11: 93-102.

16. Hack TF, Degner LF, Watson P, Sinha L. Do patients benefit from participating in medical decision making? Longitudinal follow-up of women with breast cancer. Psycho-Oncol 2006;15:9-19.

17. Gattellari M, Butow PN, Tattersall MHN. Sharing decisions in cancer care. Soc Sci Med 2001;52: 1865-1878.

18. Hack TF, Pickles T, Bultz BD, Ruether JD, Weir LM, Degner LF et al. Impact of providing audiotapes of primary adjuvant treatment consultations to women with breast cancer: a multi-site, randomized, controlled trial. J Clin Oncol 2003;21:4138-4144.

19. Hack TF, Pickles T, Bultz BD, Ruether JD, Degner LF. Impact of providing audiotapes of primary treatment 
consultations to men with prostate cancer: a multi-site, randomized, controlled trial. Psycho-Oncol 2007;16: $543-552$.

20. Degner LF, Kristjanson LJ, Bowman D, Sloan JA, Carriere $\mathrm{KC}$, O'Neil $\mathrm{J}$ et al. Information needs and decisional preferences in women with breast cancer. JAMA 1997;277:1485-1492.

21. Degner LF, Russell CA. Preferences for treatment control in adults with cancer. Res Nurs Health 1988;11:367-374.

22. Degner LF, Sloan JA. Decision-making during serious illness: what role do patients really want to play? J Clin Epidemiol 1992;45:941-950.

23. McNair DM, Lorr M, Droppleman LF. Manual for the Profile of Mood States. Educational and Industrial Testing Service: San Diego, CA, 1971.

24. Cella D. Manual of the Functional Assessment of Chronic Illness Therapy (FACIT) Measurement System (Version 4). Evanston Northwestern Healthcare and Northwestern University, Evanston, IL, 1997.

25. Reddon JR, Marceau R, Holden RR. A confirmatory evaluation of the profile of mood states: convergent and discriminant item validity. $J$ Psychopathol Behav Assess 1985;7:243-259.

26. Brady MJ, Cella DF, Mo F, Bonomi AE, Tulsky DS, Lloyd SR et al. Reliability and validity of the functional assessment of cancer therapy-breast quality-of-life instrument. J Clin Oncol 1997;15:974-986.

27. Cella DF, Tulsky DS, Gray G, Sarafian B, Linn E, Bonomi A et al. The functional assessment of cancer therapy scale: development and validation of the general measure. J Clin Oncol 1993;11:570-579.

28. Esper P, Mo F, Chodak G, Sinner M, Cella D, Pienta KJ. Measuring quality of life in men with prostate cancer using the functional assessment of cancer therapyprostate instrument. Urology 1997;50:920-928.

29. Hummel TJ, Sligo J. An empirical comparison of univariate and multivariate analysis of variance procedures. Psychol Bull 1971;76:49-57.

30. Street Jr RL, Gordon HS, Ward MM, Krupat E, Kravitz RL. Patient participation in medical consultations: why some patients are more involved than others. Med Care 2005;43:960-969.

31. Jacobsen PB, Donovan KA, Trask PC, Felishman SB, Zabora J, Baker F, Holland JC. Screening for psychologic distress in ambulatory cancer patients. Cancer 2005; 103:1494-1502.

32. Land SR, Kopec JA, Yothers G, Anderson S, Day R, Tang G, Ganz PA, Fisher B, Wolmark N. Health- related quality of life in axillary node-negative, estrogen receptor-negative breast cancer patients undergoing $\mathrm{AC}$ versus CMF chemotherapy: findings from the National Surgical Adjuvant Breast and Bowel Project B-23. Breast Cancer Res Treat 2004;86:153-164.

33. Peppercorn J, Herndon II J, Kornblith AB, Peters W, Ahles T, Vredenburgh J, Schwartz G, Shpall E, Hurd DD, Holland J, Winer E. For the cancer and leukemia group B (CALGB) and the southwestern oncology group (SWOG). Quality of life among patients with stage II and III breast carcinoma randomized to receive high-dose chemotherapy with autologous bone marrow support or intermediate-dose chemotherapy. Cancer 2005;104:1580-1589.

34. Fallowfield L, Bliss JM, Porter LS, Price MH, Snowdon CF, Jones SE, Coombes RC, Hall E. Quality of life in the intergroup exemestane study: a randomized trial of exemestane versus continued tamoxifen after 2 to 3 years of tamoxifen in postmenopausal women with primary breast cancer. J Clin Oncol 2006;24:910-917.

35. Fallowfield L, Cella D, Cuzick J, Francis S, Locker G, Howell A. Quality of life of postmenopausal women in the arimidex, tamoxifen, alone or in combination (ATAC) adjuvant breast cancer trial. J Clin Oncol 2004;22:4261-4271.

36. Gaston CM, Mitchell G. Information giving and decision-making in patients with advanced cancer: a systematic review. Soc Sci Med 2005;61:2252-2264.

37. Scott JT, Karmsen M, Prictor MJ, Entwistle VA, Sowden AJ, Watt I. Recording or summaries of consultations for people with cancer. The Cochrane Library, Issue 2, 2007. Wiley.

38. Bultz BD, Carlson L. Emotional distress: the sixth vital sign in cancer care. J Clin Oncol 2005;10:6440-6441.

39. Carver C. Enhancing adaptation during treatment and the role of individual differences. Cancer 2005;104 (11 suppl):2602-2607.

40. Steinberg ML, Fremont A, Khan DC, Huang D, Knapp H, Karaman D, Forge N, Andre K, Chaiken LM, Streeter OE. Lay patient navigator program imple mentation for equal access to cancer care and clinical trials: essential steps and initial challenges. Cancer 2006;107: 2669-2677.

41. Vodermaier A, Caspari C, Koehm J, Kahlert S, Ditsch N, Untch $\mathrm{M}$. Contextual factors in shared decision making: a randomized controlled trial in women with strong suspicion of breast cancer. $\mathrm{Br} J$ Cancer 2009;100:590-597. 